\title{
Topographic enhancement of long waves generated by an idealized moving pressure system
}

\author{
ALEJANDRO ORFILA ${ }^{1}$ SALVADOR BALLE $^{1}$ and GONZALO SIMARRO ${ }^{2,3}$ \\ ${ }^{1}$ Marine Technologies and Operational Oceanography Department, IMEDEA (CSIC-UIB). Miquel Marquès 21, \\ 07190 Esporles, Spain. E-mail: aorfila@imedea.uib-csic.es \\ ${ }^{2}$ Department of Civil Engineering, University of Castilla-La Mancha, Avenida Camilo Jose Cela s/n, \\ 13071 Ciudad Real, Spain. \\ ${ }^{3}$ Present address: Institut de Ciències del Mar (ICM-CSIC), Marine Geology Department, \\ Passeig Maritim de la Barceloneta, 08003 Barcelona. Spain
}

\begin{abstract}
SUMMARY: We studied the influence of the topography on the oceanic response to a traveling atmospheric disturbance and the relevance of its propagation direction on the generation of seiche oscillations. A primitive equation ocean model was used to analyze the response of two harbors located in insular systems to a pressure disturbance. The spectral component at the frequency of fundamental harbor resonance was determined from these data for different propagation directions of the incoming atmospheric disturbance. A conceptual model of interferences of resonantly generated ocean waves was introduced in order to explain energy maxima obtained by the numerical model close to the most affected areas.
\end{abstract}

Keywords: meteotsunami, long wave, rissaga.

RESUMEN: AMPLIFICACIÓN TOPOGRÁFICA DE ONDAS LARGAS GENERADAS POR UNA PERTURBACIÓN ATMOSFÉRICA VIAJANDO. - En este trabajo estudiamos la influencia de la topografía en la respuesta oceánica generada por una perturbación atmosférica en movimiento y la importancia de la dirección de propagación de ésta en la generación de meteotsunamis. Para ello, se analiza la respuesta de la superficie del mar en la bocana de dos puertos ubicados en sistemas insulares utilizando un modelo de circulación de ecuaciones primitivas. Para diferentes ángulos de incidencia de la perturbación atmosférica, se estudia la amplitud de la respuesta espectral a la frecuencia de resonancia de cada uno de los puertos. Los resultados numéricos proporcionan amplificaciones máximas en cada uno de los puertos para ángulos que concuerdan con las observaciones.

Palabras clave: meteotsunamis, ondas largas, rissaga.

\section{INTRODUCTION}

Meteotsunamis are large-amplitude sea level oscillations of meteorological origin with characteristic periods similar to those of seismic tsunamis (Montserrat and Thorpe, 1992; Shillington, 1984; Mercer et al., 2002). These oscillations have been related to the passage of fast moving tropical storms, frontal zones, atmospheric pressure jumps and trains of atmospheric gravity waves. The forcing mechanism is a fast moving (i.e. in the order of tenths of meters per second) mesoscale pressure disturbance propagating over the ocean that generates a free surface water wave by an inverse barometer mechanism. When the generated long wave approaches the coast its amplitude increases due to shoaling. The amplified wave may strongly excite some of the normal modes of given bays or inlets and thereby generate seiches.

Meteorological tsunamis and seiches are regularly observed in several locations and have been reported in many works. For instance, Hodzic (1979) identified at least three events during one year with amplitude oscillations as large as $2.5 \mathrm{~m}$ in the Adriatic Sea; Papadopoulos (1992) observed similar oscillations along the coast of Greece; Rabinovich and Monserrat (1996) reported oscillations of $20 \mathrm{~cm}$ in the bays of Shiko- 
tan Island (South Kuril Islands, northwestern Pacific); Monserrat et al. (1998) described sea level oscillations of $1.2 \mathrm{~m}$ in Ciutadella harbor (Menorca Island, western Mediterranean Sea); and Candela et al. (1999) reported oscillations of $1.5 \mathrm{~m}$ in Mazzara del Vallo (Sicily Strait).

Several seiche events associated with meteotsunamis have been thoroughly documented in two insular systems surrounded by complex bathymetries: Ciutadella harbor in Menorca Island (Balearic Archipelago, western Mediterranean Sea) and Krabovaya Bay in Shikotan Island (Kuriles Archipelago, northwestern Pacific). Extensive field data records which provide a general overview of the characteristics of the traveling atmospheric disturbances that trigger these events are available for both sites.

Ciutadella harbor is a natural, elongated inlet about $1000 \mathrm{~m}$ long and $90 \mathrm{~m}$ wide located on the southwestern side of Menorca Island (see dot in Fig. 1, left). Large oscillations known as rissaga are periodically observed at this location with trough-to-crest amplitudes that have reached more than $2 \mathrm{~m}$. Several instruments have been deployed here since 1988 to obtain high quality bottom and free surface pressure records inside the harbor and on the shelf (Marcos et al., 2009).

Monserrat and Thorpe (1992) used the surface pressure time series from an array of micro-barographs to obtain the wavelength, phase speed and propagation direction of the atmospheric perturbation. From the analysis of several rissaga events that occurred in the summer of 1992, Garcies et al. (1996) found that the atmospheric perturbations capable of generating rissaga events typically come from the SW with a velocity between 25 and $30 \mathrm{~m} / \mathrm{s}$. Rissaga phenomena excite the fundamental mode of the harbor, whose period is around 10.5 minutes. It is accepted that they are forced by long waves generated by atmospheric pressure disturbances traveling along the continental shelf surrounding the island of Mallorca.

A similar phenomenon, called yota, is observed at Shikotan Island, in the region of the Kuril Islands on the southwestern shelf of Kamchatka (Fig. 1, right). A set of inshore micro-barographs and bottom pressure stations were deployed to monitor these events in this area (Kovalev et al., 1991; Djumagaliev and Rabinovich, 1993). Krabovaya Bay, a narrow elongated inlet oriented to the NW, about $2800 \mathrm{~m}$ long and 700 $\mathrm{m}$ wide, located on the north coast of Shikotan Island (see dot on Fig. 1 right), was found to experience large sea-level oscillations. The analysis of Rabinovich and Monserrat (1998), hereafter (RM98), showed that the atmospheric disturbances for the most energetic events were traveling from the $\mathrm{SW}$ at a velocity of $15 \mathrm{~m} / \mathrm{s}$. The fundamental mode of Krabovaya Bay was determined to be around 28.5 minutes.

A number of studies carried out worldwide (see, for instance, the recent special issue edited by Rabinovich, et al. (2009)) indicate that these phenomena appear when three main conditions are met: i) in all cases, the forcing mechanism is a sudden atmospheric disturbance traveling across the sea (Belusic and Mahovic, 2009; Mercer, 2002); ii) the phase celerity $c_{p}$ of these atmospheric perturbations is close to the Proudman resonance condition (Proudman, 1929), i.e. the Froude number defined as the ratio between phase celerity $c_{p}$ and the characteristic long wave celerity $C=\sqrt{g h}$, is close to one; and iii) the disturbance generated at the mouth of the inlet or harbor has a substantial spectral power in the band corresponding to the fundamental mode of the harbor or inlet.

The first two conditions are necessary for generating meteotsunamis, while the third one is specifically related to seiche generation within the inlets. In addition, Honda et al. (1908) noted that the most dramatic events occur mainly in long, shallow and narrow mouthed inlets. For these geometries the frequencies of the normal modes of oscillation, proportional to the square root of the inlet depth and inversely proportional to its length, are closer to the usual most energetic frequencies of the meteotsunamis.

In the present work we studied the influence of the direction of the atmospheric perturbation on the generation of seiche oscillations in Ciutadella harbor and Krabovaya Bay, which has proven to be a key factor for triggering meteotsunami events (Vilibic, 2008). We use a numerical model with an artificial pressure jump traveling close to the resonant Froude number in order to determine the free-surface elevations in the study areas. The spectral component at the frequency of fundamental harbor resonance was determined from these data for different propagation directions of the incoming atmospheric disturbance. The numerical results yield the maximum amplitude of the resonant component for directions that match the experimental observations.

\section{MATERIALS AND METHODS}

Long wave oscillations of the water free surface in an enclosed bay, harbor or port appear in response to sea level oscillations at the mouth. In linear wave theory, the wave amplitude inside the inlet can be linearly related to that of the incoming wave as,

$$
A_{\text {in }}=G(\omega, \theta) A_{\text {out }}(\omega, \theta)
$$

where $A_{\text {in }}(\omega)$ and $A_{\text {out }}(\omega, \theta)$ are the amplitudes of the component with the angular frequency $\omega$ of the wave inside and outside the inlet respectively, with incoming direction $\theta . G(\omega, \theta)$ is the inlet's response function, which depends exclusively on the geometry of the inlet. The resonant modes of the inlet are given by the singularities of the function $G(\omega, \theta)$ in the complex plane (Mei, 1989): the real part defines the frequency of the resonant mode while the imaginary part defines the damping of the mode. When the incoming long wave has a significant amount of energy in a band close to any of the resonant modes of the bay, it will generate 


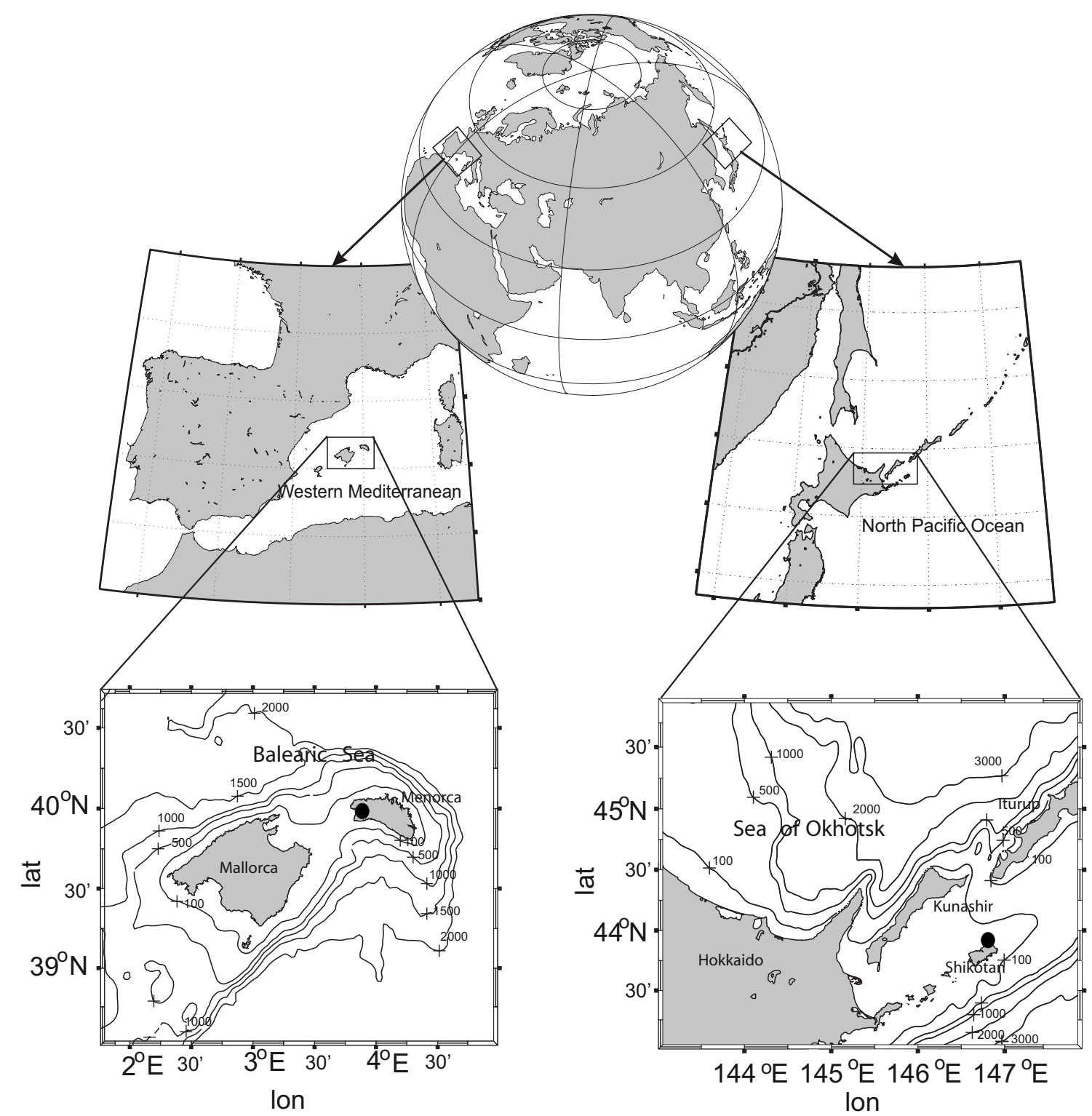

FIG. 1. - Geographic location and numerical domain (bottom) of Mallorca and Menorca Islands (left) and South Kuril Islands (right). The locations of Ciutadella and Krabobaya harbors are indicated with circles.

seiches, and the smaller the damping of the resonant mode, the larger the amplitude of the seiches.

Traveling atmospheric perturbations are efficient mechanisms that generate waves on the sea surface. As Proudman showed in 1929, when the celerity of the moving system is similar to the local wave velocity (i.e. Froude number $\sim 1$ ) then resonant transfer of energy occurs and high-amplitude (which here means amplitudes in the order of a few decimeters) waves may be generated. The wave amplitude is proportional to the distance traveled by the moving system (Nielsen, 2008).

Ciutadella harbor and Krabovobaya Bay are surrounded by large areas of almost constant depths of around 90 and 30 meters respectively (see Fig. 1, bottom panel). Therefore, pressure systems traveling with a celerity close to the local long wave velocity $\sqrt{g h}$ (i.e. around $c_{p}=30 \mathrm{~m} / \mathrm{s}$ for the case of Ciutadella and around $c_{p}=17 \mathrm{~m} / \mathrm{s}$ for Krabovaya) are expected to generate large wave amplitudes at the mouth, $A_{\text {out }}$, as repeatedly reported. Note, however, that Proudman resonance over an almost flat seabed occurs irrespective of the direction of propagation of the atmospheric perturbation, while it has been observed that significant seiche events occur only for specific propagation directions.

In order to gain deeper insight into the influence of the direction of the atmospheric forcing, we carried out numerical simulations of the free surface waves induced by a traveling pressure front by means of ROMS, a free-surface, hydrostatic, primitive equation ocean model (Song and Haidvogel, 1994). No differences in the spectra of the free surface at the grid points located 
in front of Ciutadella and Krabobaya were found using the three dimensional equations and the long wave equations.

The numerical domain for the Balearic archipelago is formed by $130 \times 90$ nodes with $2.4 \mathrm{~km}$ grid resolution and covers the islands of Mallorca and Menorca (Fig. 1, bottom left). These islands are connected by a narrow shelf, which drops off very suddenly at the $100 \mathrm{~m}$ water depth contour. The distance between the coastline and the $100 \mathrm{~m}$ contour is roughly $10-15 \mathrm{~km}$ around the islands, except in the northwest part of Mallorca where the shelf extends to Menorca.

For the Kuril Islands the mesh has $300 \times 180$ nodes with a resolution of $1.6 \mathrm{~km}$. The domain includes the southern part of the Sea of Okhotsk extending south 60 miles from Shikotan (Fig. 1, bottom right). The archipelago is in a shallow shelf which drops to deep water in a narrow slope, about $30 \mathrm{~m}$ deep to the north of the Kunashir and Iturup Islands and to the south of Shikotan.

The common geographical feature of the two regions is that the inlets are located at the end of a relatively large shelf of constant depth, which enables large amplitude waves to be generated due to Proudman resonance.

In both areas, we have imposed a traveling atmospheric pressure disturbance as the forcing mechanism at the free surface. The pressure has the analytical form of a solitary wave, e.g.

$$
p(x, y)=p_{0}+\Delta p \operatorname{sech}\left\{\frac{\phi(x, y)}{R}\right\},
$$

where $p_{0}$ is the reference atmospheric pressure, $\Delta p$ is the amplitude of the atmospheric disturbance (constant), $R$ is the characteristic width of the disturbance and $\phi(x, y)$ is the phase given by

$\phi(x, y)=\left(x-x_{0}\right) \cos \theta+\left(y-y_{0}\right) \sin \theta-c_{p} t$,

where $\theta$ is the angle of incidence measured clockwise from the north, $c_{p}$ is the phase velocity, $x_{0}$ and $y_{0}$ are the initial position of the disturbance and $t$ is time.

The time step for the numerical integration is $15 \mathrm{~s}$, which allows the resonance frequency of the harbor to be resolved accurately enough and also provide numerical stability over a large range of grid spacings. The grid size chosen in both cases resolves the atmospheric disturbance well, and we have checked that a finer grid does not exhibit differences in the relevant scales but needs more computational resources and time.

The elevation of the sea-surface in response to this traveling pressure disturbance was simulated in the two regions considered in order to elucidate the role of the propagation direction in the generation of seiches. Moreover, we also tested the working hypothesis of the matching velocities between the free surface ocean wave $C$ and the traveling atmospheric perturbation $c_{p}$ (i.e. the Proudman resonance effect).
To assess the effectiveness of this mechanism, in each area we carried out a first set of numerical experiments in which a pressure front traveling with different celerities crosses the study areas. If the areas have a constant depth then all directions are equally valid for performing the test. In our case, however, the numerical experiments were performed over given bathymetries, and hence the results depended on the chosen direction. We therefore only used the directions similar to those we know generate the seiches at the inlets under consideration, which in both cases corresponded to the third quadrant. Therefore, following Garcies et al. (1996) the propagation direction was fixed to $\theta=225^{\circ}$ for the case of Ciutadella and $\theta=240^{\circ}$ for the case of Krabovaya, according to RM98. In both cases, the width of the atmospheric pressure disturbance was set at $\mathrm{R}=9 \mathrm{~km}$.

In order to analyze the influence of the propagation direction on the generation of seiches, we performed a second set of experiments in which we modified the traveling direction of the pressure system. Guided by the reported observations in the two locations, we mainly considered directions in the third quadrant, from $180^{\circ}$ to $280^{\circ}$ equispaced by $1^{\circ}$. In this second set of experiments, in each area the velocity of the perturbation was chosen as the one that leads to the maximum amplification outside the inlet. For each direction, we recorded the complete time series for the sea-surface elevation at the nearest grid point to the harbor of interest. The last $2^{\mathrm{N}}$ points in the time series (where $\mathrm{N}=9$ in Ciutadella and $\mathrm{N}=11$ in Krabovaya) were used to compute the normalized Fourier spectrum at the harbor entrance by applying FFT. A different number of points was used at each location because the areas were different sizes and it was necessary in order to properly describe the fundamental resonance of each harbor. Finally, the total power around the fundamental harbor resonance - obtained by adding the power at this frequency to the power at the nearest frequencies - was calculated and plotted against the propagation direction.

\section{RESULTS}

\section{Influence of celerity}

Figure 2 shows the maximum free surface elevation at the node closest to the mouth of the inlets for different atmospheric perturbation velocities normalized by the local wave celerity on the shelf. In Ciutadella harbor (Fig. 2, top) the maximum amplitude is reached when the pressure front travels at $c_{p}=30 \mathrm{~m} / \mathrm{s}$, while in Krabovaya Bay (Fig. 2, bottom), the maximum amplitude is obtained when the velocity of the front is around $c_{p}=17 \mathrm{~m} / \mathrm{s}$. Not surprisingly, these results agree quite well with the long wave propagation celerities at each platform, which are respectively, $C=\sqrt{g 90 m} \approx 30$ $\mathrm{m} / \mathrm{s}$ and $C=\sqrt{g 30 m} \approx 17 \mathrm{~m} / \mathrm{s}$, in spite of the fact that we are using real bathymetries. It is noteworthy that the resonance seems narrower in the case of the Kuril 

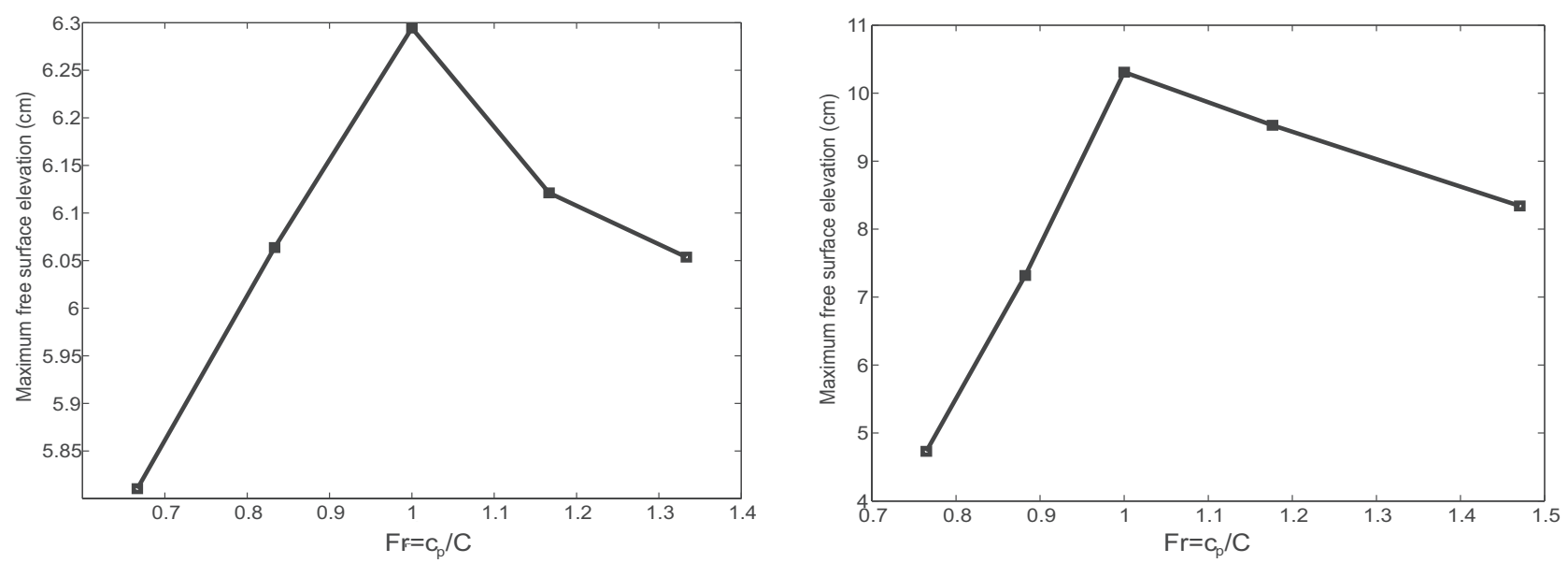

FIG. 2. - Free surface elevation (cm) in front of Ciutadella harbor (top) for different Froude numbers. The same for Krabovaya Bay (bottom).

Islands than in the Balearic archipelago, which can be attributed to the larger depth variations in the former compared to the latter.

\section{Influence of propagation direction}

\section{Ciutadella Harbor}

In order to test the influence of the propagation direction of the atmospheric perturbation for the Balearic Islands, the phase speed was set to $c_{p}=30 \mathrm{~m} / \mathrm{s}$. Different cases with incidence angles at intervals of $1^{\circ}$ from the south $\left(\theta=180^{\circ}\right)$ to the west-northwest $\left(\theta=280^{\circ}\right)$ were propagated into the domain. The simulation lasted 10 hours, which is sufficient for at least sixteen periods of the longest (30 minutes) edge wave generated by the local geometry after the traveling perturbation leaves the numerical domain.

Snapshots of the numerical results for a perturbation traveling from the $\mathrm{SW}\left(\theta=210^{\circ}\right)$ are shown in Figure 3 at 15 minute intervals. As the wake interacts with the shelf of the southern island (Mallorca), trapped waves are generated that travel along its coast. As already noted by Vennell (2010), disturbances crossing the shelf at particular angles generate transients that are trapped on the shelf by internal reflection. These edge waves have already been observed in field experiments (Garcies et al., 1996) and analytically predicted for the case of the Balearic Islands (Liu et al., 2002). When the disturbance passes the channel that separates the two islands a lower trapped wave mode is formed between the islands (Fig. 3, middle panel). As the perturbation passes the area, trapped waves are also generated around the northern island (Menorca) (Fig. 3, bottom panel). The largest free surface amplitude is observed in front of Ciutadella harbor when the front passes Menorca Island (Fig. 3, middle panel, left).

The resonant component of the sea-surface elevation at the node located in front of Ciutadella was computed for the different incoming directions and
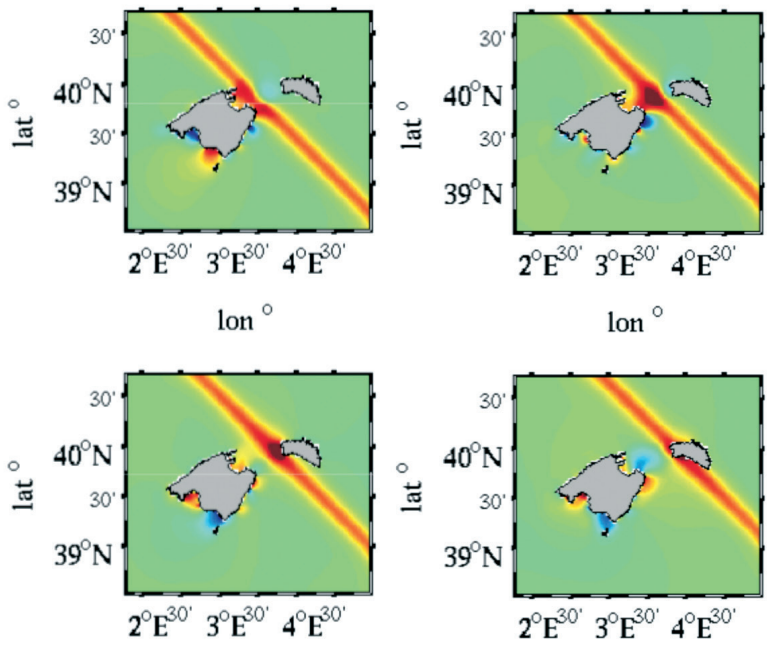

lon ${ }^{\circ}$

$\operatorname{lon}^{\circ}$
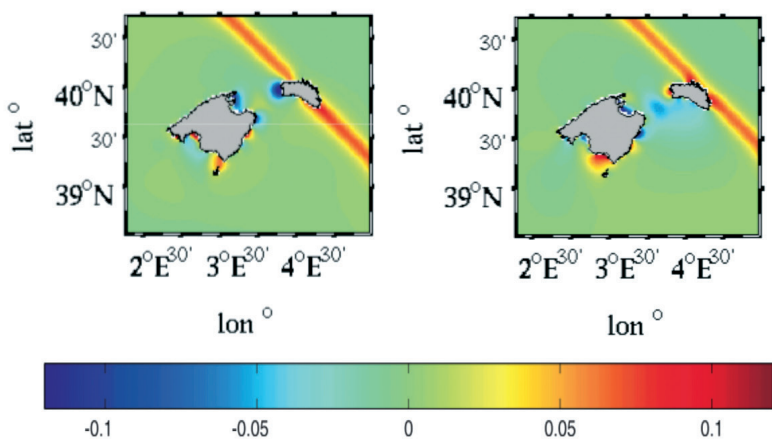

lon ${ }^{\circ}$

FIG. 3. - Snapshots of the free surface response to the pressure disturbance around the islands of Mallorca and Menorca for a perturbation arriving from $\theta=240^{\circ}$. Snapshots are displayed at 15 minute intervals.

smoothed using a three degree running average (Fig. 4). A very broad feature appears for directions between $220^{\circ}$ and $250^{\circ}$, with a maximum at $235^{\circ}-240^{\circ}$, and there are additional but substantially narrower peaks for other directions. 


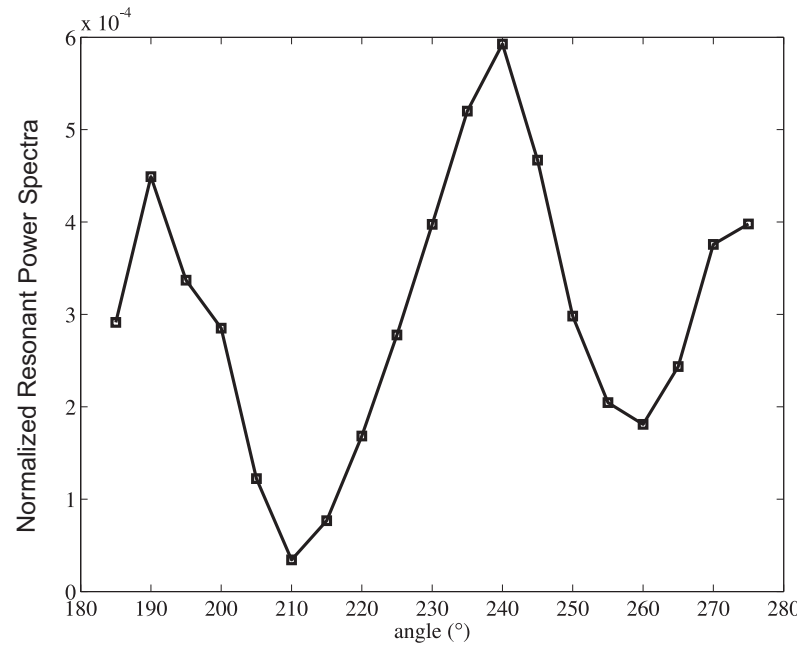

FIG. 4. - Normalized (by the total power for each angle) Resonant Power Spectra around the fundamental resonance frequency (10.5 min) for Ciutadella harbor.
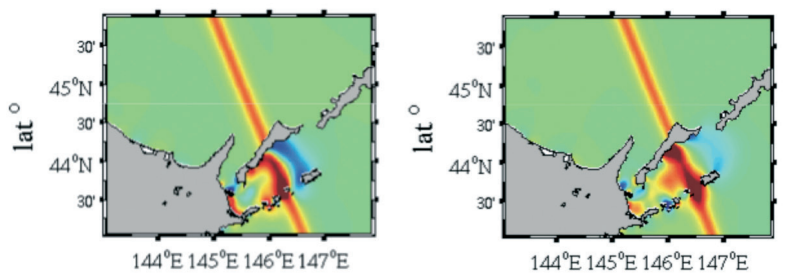

lon ${ }^{\circ}$

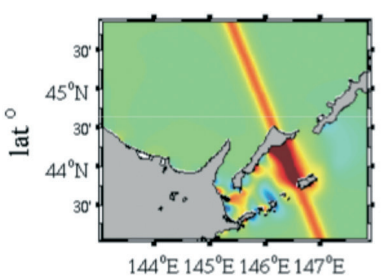

$\operatorname{lon}^{\circ}$

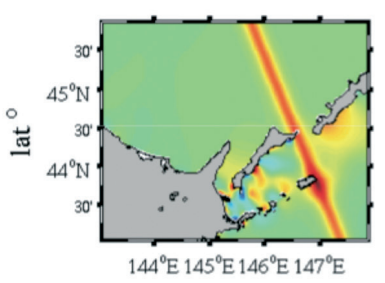

lon ${ }^{\circ}$

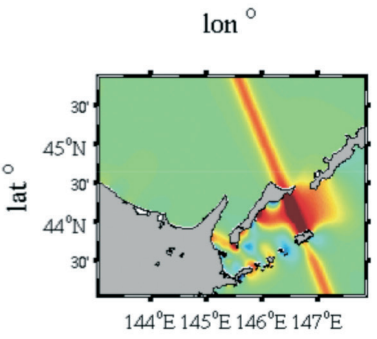

$\operatorname{lon}^{\circ}$

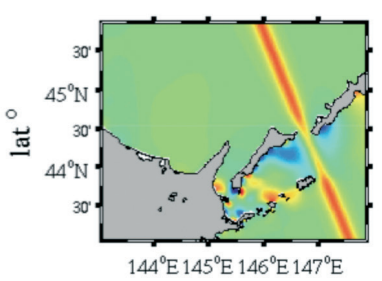

$\operatorname{lon}^{\circ}$

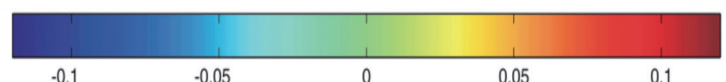

FIG. 5. - Snapshots of the free surface response to the pressure disturbance in the South Kuril Islands for a perturbation arriving from $\theta=255^{\circ}$. Snapshots are displayed at 40 minute intervals.

\section{Krabobaya Bay}

For Shikotan, the phase speed of the pressure disturbance was taken according to available records as

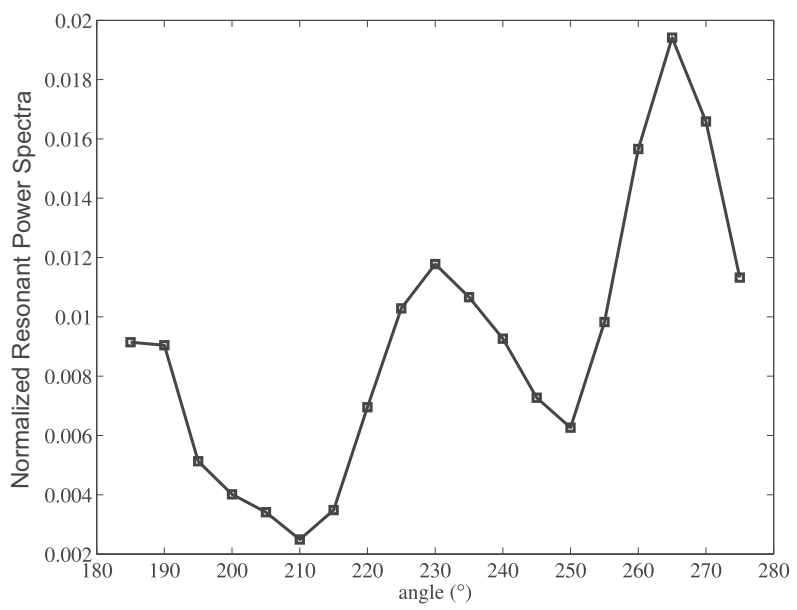

FIG. 6. - Normalized (by the total power for each angle) Resonant Power Spectra around the fundamental resonance frequency for Krabovaya Bay (28.5 min). Normalization was based on the total power for each angle.

$c_{p}=17 \mathrm{~m} / \mathrm{s}$. Similarly to the Balearic Islands simulations, different cases with incidence angles at intervals of $1^{\circ}$ from the south $\left(\theta=180^{\circ}\right)$ to west-northwest $(\theta=$ $\left.280^{\circ}\right)$ were propagated into the domain. Simulations were run for 20 hours, which again was sufficient time for all the waves to develop in a similar way to the previous case.

The free surface elevations for a perturbation traveling from the W-SW $\left(\theta=255^{\circ}\right)$ are shown in Figure 5 at 40 minute intervals. As the perturbation travels across the southern part of the Sea of Okhotsk, edge waves trapped in the shelf of the northern part of Hokkaido Island travel to the south (Fig. 5, top and middle panels). When the pressure front arrives to the shallow area between the two northern islands (Kunashir and Iturup) and Shikotan, edge waves are generated and interact with each other due to the complex geometry of the area (Fig. 5, bottom). As expected from the conditions simulated, the largest amplitude was obtained in Krabovaya just when the front passed the Island (Fig. 5, middle panel right).

The resonant component of the different power spectra for all incoming directions was calculated from the model output at the grid point located in front of Krabovaya Bay. Figure 6 shows the normalized power spectra with a 5 degrees interval smoothed with a 3 degree running average. It can be seen that there is a broad maximum for incidence directions between $220^{\circ}$ and $245^{\circ}$, a narrower maximum between $255^{\circ}$ and $275^{\circ}$, and a third and still narrower peak at $185^{\circ}$.

\section{DISCUSSION}

The numerical results obtained in the previous section are in good agreement with observations and confirm that the maximum wave amplitude is achieved when the pressure front travels with a celerity that matches the local shallow water wave velocity in the surrounding areas of the inlets. This evidences the 

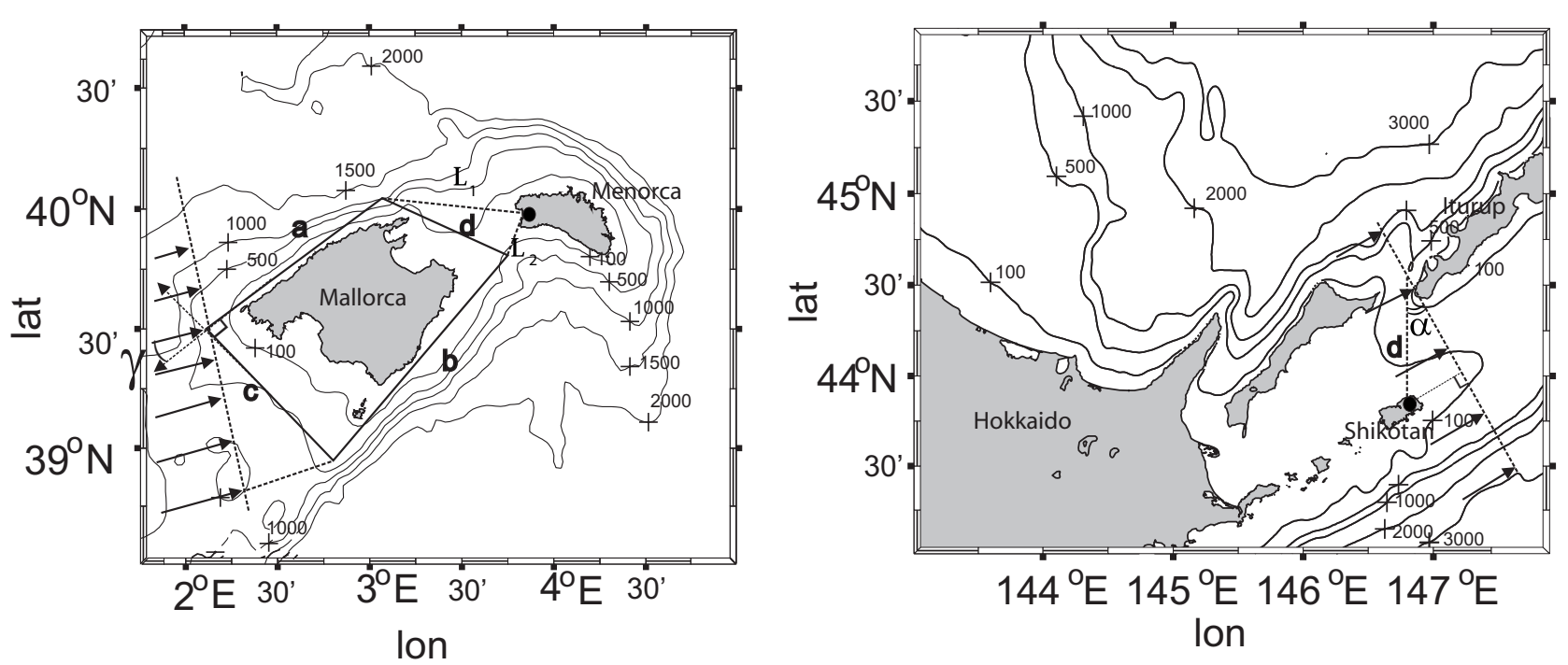

FIG. 7. - Geometry defined in the analytical model for interferences between waves around the Balearic Islands (left) and for the Kuril Islands (right).

important role played by Proudman resonance in the emergence of large amplitude seiches. Marcos et al. (2003) showed that the largest seiches inside Ciutadella were produced by disturbances of $25 \mathrm{~m} / \mathrm{s}$ by simulating pressure systems with an incoming wave direction of $225^{\circ}$ and different celerities. Vilibic et al. (2008) studied numerically an intense rissaga event by simulating real pressure data from microbarographs. They obtained very good agreement with the free surface response inside Ciutadella (either in the magnitude or the travel arrival time). They also quantified the different amplification mechanisms of the forced wave along its path (as the sum of the Proudman resonance, the shoaling by depth, which can be obtained by Green's law, and the non-linear amplification within the inlet).

In this work, we observed that the propagation direction of the perturbation largely determines the final oscillation amplitude of the resonant component at the entrance of the harbor.

The directions that yielded maxima in the amplitude of the sea level oscillations at the entrance of each harbor were also in good accordance with the reported observations. This influence has already been reported by Vilibic et al. (2008), who modified the direction of the June 2006 rissaga event and found that the largest amplification (depending on the analyzed grid point) was produced by disturbances traveling with celerities between 25 and 30 $\mathrm{m} / \mathrm{s}$ in directions between 225 and $240^{\circ}$.

Recently, Venell (2010) pointed out the importance of the incident angle crossing a shelf or coast, showing that atmospheric pressure disturbances moving with speeds less than the shallow water wave celerity approaching the shelf at a critical angle, given by the inverse sine of the Froude number of the disturbance, increase the Proudman resonance. This work also shows that beyond small angles of incidence, transients generated by disturbances crossing deep to shallow waters will be trapped on the shelf. These coastal trapped free waves can be of crucial significance for harbor amplifications if they have periods that are multiples of the fundamental modes of the inlets. Liu et al (2002) analytically obtained the edge waves on a circular shelf with a circular island in the middle, and compared the solutions with observed spectra in the Balearic Islands. They showed that the peaks in the observed spectra can be identified as the fundamental modes of the edge waves, and that the magnitude of the second peak becomes higher with Froude number 1. The direction of the traveling pressure system was not studied in this work due to the cylindrical symmetry of the problem.

Besides the Snell-like reflection effect explained by Vennell (2010), the topography of the two locations analyzed in the present paper might explain some of the amplification observed at the mouth of each inlet. The numerical results in the case of Ciutadella show that the shelf around the southern island (Mallorca) acts as a 'guide', trapping waves which travel along the shore. These transient waves are near the resonant Froude number but not necessarily 1 (due to changes in real bathymetry that are not always constant). When these waves reach the platform connecting the islands of Mallorca and Menorca, they can freely propagate to Ciutadella over the almost flat seabed in this area.

As shown in Figure 7 (left), in which Mallorca Island has been simplified to a polygon with faces $a, b, c$ and $d$, the amplitude of a monochromatic wave in front of Ciutadella harbor can be considered as the sum of the waves radiated from the edges of Mallorca Island on both sides. The addition will be constructive if the difference in the times required to reach Ciutadella harbor is a multiple of the period of the fundamental mode of the harbor, T. According to Figure 7 (left), this means:

$$
m T=\frac{c \sin \gamma_{m}+b+L_{2}-a-L_{1}}{C},
$$


where $\mathrm{m}=0, \pm 1, \pm 2, \pm 3, \ldots, L_{1}$ and $L_{2}$ are the distance between the vertices located on the north side of Mallorca Island and Ciutadella, and $C=\sqrt{g h}$ is the local celerity of the water wave on the shelf. Therefore, for angles $\gamma_{m}$ satisfying the above relationship, the two waves interfere constructively and increase the amplitude of the free surface oscillations (which might already be large due to Proudman resonance) at the entrance of the harbor. Following the definition of $\gamma$ in Figure 7 (left), this corresponds to incidence angles of constructive interference

$$
\theta_{m} \approx 225^{\circ}+\gamma_{m}
$$

In the case of the rissaga events at Ciutadella harbor, the fundamental resonance period is $T \approx 10.5 \mathrm{~min}$ and the wave velocity is $C \approx 30 \mathrm{~m} / \mathrm{s}$. In addition, $a+L_{1^{-}}$ $b-L_{2} \approx 14 \mathrm{~km}$ and $c \approx 80 \mathrm{~km}$, which leads to constructive interference for incidence angles

$\theta_{\mathrm{m}}=185^{\circ}, 203^{\circ}, 218^{\circ}, 232^{\circ}, 245^{\circ}, 260^{\circ}, 275^{\circ}$ and $297^{\circ}$.

It is worth noting that even though the increase in constructive interference does not take into account the amplitudes of the interfering waves, the results are in agreement with the numerical results. Although the analytical models provide more possible directions, some of them collapsed in the numerical results. In fact, the two first values correspond to the isolated peaks at the top of Figure 4, around $185^{\circ}$ and $195^{\circ}$. The peak around $270^{\circ}$ in the numerical experiments corresponds to the angles $260^{\circ}$ and $270^{\circ}$ of the analytical model. Finally, the broad peak between $220^{\circ}$ and $250^{\circ}$ at the top of Figure 4 corresponds to the peaks at $218^{\circ}, 232^{\circ}$ and $245^{\circ}$.

The interferometric explanation can be further tested by analyzing the case of Shikotan Island, in which a simplified geometry for the analytical model is displayed in Figure 7 (right). For an incoming wave with an angle $\alpha$, the addition of the incident wave that arrives at Shikotan and the secondary wave radiated from the strait between the islands of Kunashir and Iturup will be constructive if the difference in the arrival times to the mouth of the harbor of both waves is a multiple of the harbor resonant period. Following the definition provided in Figure 7 (right), this can be expressed as,

$$
m T=\frac{d+d \sin \alpha_{m}}{C},
$$

where $m$ is an integer, $C$ the celerity of the free surface atmospherically forced long wave and $\mathrm{d}$ is the distance between the islands of Iturup and Shikotan. Taking the pressure front velocity to be the same as the free surface ocean wave (depths around $30 \mathrm{~m}$ ), i.e. $C \approx 17$ $\mathrm{m} / \mathrm{s}$, the fundamental period of seiche oscillation $T \approx 29$ min and $d \approx 60 \mathrm{~km}$ leads to constructive interference for incidence angles

$$
\theta_{\mathrm{m}} \approx 270^{\circ}-\alpha_{\mathrm{m}}=194^{\circ}, 241^{\circ} \text { and } 270^{\circ} .
$$

Again, these values are in good agreement with the numerical results in Figure 4 (right), in which maximum resonance occurs in the directions of $185^{\circ}, 230^{\circ}$ and $265^{\circ}$.

The analysis based on constructive interferences is a theoretical simplification of the real cases. Two points have to be addressed with regards to the real meteotsunami phenomena. First, traveling pressure disturbances are highly spatially variable. For instance several studies on traveling pressure disturbances that generate meteotsunamis found the core of the atmospheric disturbance to have a maximum width of $50 \mathrm{~km}$ (Sepic et al., 2009; Vilibic et al., 2010). Secondly, the celerity of free waves depends on the bathymetry and in real bathymetry waves are not propagated at the same speed on both sides of Mallorca and in the entire basin surrounding Shiko$\tan$. This means that the analytical model has to be seen as a possible contribution to the amplification of the free waves near the Proudman resonance at the mouth of the harbors.

\section{CONCLUSIONS}

We studied the influence of the celerity and direction of the atmospheric perturbation on the generation of seiche oscillations. We simulated numerically the response of two harbors located in insular systems to an analytical pressure disturbance by integrating a numerical model for different celerities and propagation directions. For a fixed propagation direction, the maximum wave amplitude at the entrance of the inlets was obtained when the celerity of the atmospheric disturbance was close to the velocity of the shallow water waves. For fixed propagation celerity, we analyzed the influence of the propagating direction of the atmospheric disturbance on seiche generation. We found that the amplitude of the sea-surface oscillation at the entrance of the harbor depends strongly on the geometry of the area. In the two cases considered, the numerical results yield the maximum amplitude of the resonant component for directions that match the experimental observations.

A simple analytical model based on interference theory is presented to explain some of the contribution of the incoming angle direction of the atmospheric perturbation on the amplification at the harbor entrance. These results can be used to easily discard events when operational systems are implemented for preventing the effects of large seiche events in areas where complex geometry amplifies incoming long waves. In order to fully describe and predict meteotsunami events it is necessary to study the topographical effects and conditions regarding the incoming angle that cause trapped waves. Research into the energy transfer between the atmosphere and the ocean and the nonlinear effects between the shelf and the inlets is also necessary. 


\section{ACKNOWLEDGEMENTS}

The authors are grateful for financial support from the Spanish MICINN through the projects CTM200612072 and CTM2010-16915, and from the Port de les Balears (Balearic Islands Government). Comments from Drs. S. Monserrat, M. Olabarrieta, J. Tintore and M. Marcos are greatly acknowledged. Kind advice from Dr. I. Vilibic and an anonymous referee helped to improve the final version of the manuscript.

\section{REFERENCES}

Belusic, D. and N.S. Mahovic. - 2009. Detecting and following atmospheric disturbances with a potential to generate meteotsunamis in the Adriatic. Phys. Chem. Earth., 17-18: 918-927.

Candela, J., S. Mazzola, C. Sammari, R. Limeburner, C.J. Lozano, B. Patti, and A. Bonnano. - 1999. The"Mad Sea"phenomenon in the Strait of Sicily. J. Phys. Oceanogr., 29: 2210-2231.

Djumagaliev, V.A. and A.B. Rabinovich. - 1993. Long wave investigation at the shelf and in the bays of the south kuril Islands. $J$. Korean Soc. Coastal Ocean Eng., 5: 318-328.

Garcies, M., D. Gomis and S. Monserrat. - 1996. Pressure-forced seiches of large amplitude in inlets of the Balearic Islands. Part II: Observational study. J. Geophys. Res., 101(C3): 6453-6467.

Honda, K., T. Terada, Y. Yoshida and D. Isitani. - 1908. An investigation on the secondary ondulations of oceanic tides. J. College Sci. Imp. Univ. Tokio.

Kovalev, P. D., A. B. Rabinovich and G.V. Shevchenko. - 1991. Investigation of long waves in the tsunami frequency band on the southwestern shelf of Kamchatka. Nat. Haz. 4(2-3): 141-159.

Liu, P.L.-F., S. Monserrat and M. Marcos. - 2002. Analytical simulation of edge waves observed around the Balearic Islands. Geophys. Res. Let, 29, 17: 1847, doi: 10.1029/2002GL015555.

Marcos, M., S. Monserrat, R. Medina and C. Vidal. - 2003. Influence of the atmospheric wave velocity in the coastal amplification of meteotsunamis. In A. C. Yalciner, E.N. Pelinovsky, C.E. Synolakis and E. Okal (eds.), Submarine Landslides and Tsunamis, pp. 247-253. Kluwer Acad. Publ.

Marcos, M., S. Monserrat, R. Medina, A. Orfila and M. Olabarrieta. -2009 . External forcing of meteorological tsunamis at the coast of the Balearic Islands. Phys. Chem. Earth., 17-18: 938-947.

Marcos, M., P.L.-F. Liu and S. Monserrat. - 2004. Nonlinear resonant coupling between two adjacent bay. J. Geophys. Res., 109 (C05008), doi:10.1029/2003JC002039.

Mei, C.C. - 1989. The applied dynamics of ocean surface waves. World Scientific. Singapore.

Mercer, D., J. Sheng, R. J. Greatbatch and J. Bobanovic. - 2002. Baro- tropic waves generated by storms moving rapidly over shallow water. J. Geophys. Res., 107(C10), doi:10.1029/2001JC001140.

Monserrat, S. and A.J. Thorpe. - 1992. Gravity wave observations using an array of microbarographs in the Balearic Islands. $Q . J$. R. Meteorol. Soc., 118: 259-282

Monserrat, S., A.B. Rabinovich and B. Casas. - 1998. On the reconstruction of the transfer function for atmospherically generated seiches. Geophys. Res. Let., 12: 2197-2200.

Nielsen, P., S. de Brye, D.P. Callaghan and P.A. Guard. - 2008. Transient dynamics of storm surges and other forced long waves. Coast. Eng. 55(6): 499-505.

Papadopoulos, G.A. E. Polymenakos, M. Tsimplis and G. Vlachakis. - 1992. An exceptional seawave observed in the Aegean: A geological or meteorological event? XVII EGS General Assembly, Edinburgh, C109.

Proudman, J. - 1929. The effects on the sea of changes in atmospheric pressure. Geophysical supplement to Mon. Not. R. Astron. Soc. 2,(4): 197-209

Rabinovich, A.B. and S. Monserrat. - 1996. Meteorological tsunamis near the Balearic and Kuril Islands: descriptive and statistical analysis. Nat. Haz. 13: 55-90.

Rabinovich, A.B. and S. Monserrat. - 1998. Generation of meteorological tsunamis (large amplitude seiches) near the Balearic and Kuril islands. Nat. Haz. 18: 27-55.

Rabinovich, A.B., I. Vilibic and S. Tinti. - 2009. Meteorological Tsunamis: Atmospherically Induced Destructive Ocean Waves in the Tsunami Frequency Band. Phys. Chem. Earth., 34, 17-18: 891-1032.

Sepic, J., I. Vilibic and D. Belusic. - 2009. The source of the 2007 meteotsunami (Adriatic Sea). J. Geophy. Res., 114, C03016, doi:10.1029/2008JC005092.

Shillington, F.A. - 1984. Long period edge waves off Southern Africa. Cont. Shelf Res., 3: 343-357.

Song, Y. and D.B. Haidvogel. - 1994. A semi-implicit ocean circulation model using a generalized topography-following coordinate system. J. Comp. Phys., 115(1): 228-244.

Vilibic, I., S. Monserrat, A. B. Rabinovich and H. Mihanovic. 2008. Numerical modelling of the destructive meteotsunami of 15 June, 2006 on the coast of the Balearic Islands. Pure Appl. Geophys., 165: 2169-2195.

Vilibic, I., J. Sepic, J. Ranguelov, N. Strelec-Mahovic and S. Tinti. - 2010. Possible atmospheric origin of the 7 May 2007 western Black Sea shelf tsunami event. J. Geophys. Res., 115, C07006, doi:10.1029/2009JC005904.

Vennell, R.-2010. Resonance and trapping of topographic transient ocean waves generated by a moving atmospheric disturbance. $J$. Fluid Mechanics, 650: 427-442.

Scient. ed.: J. Font.

Received September 14, 2010. Accepted February 7, 2011.

Published online June 8, 2011. 